\title{
The influence of prematurity on the development of phonological skills
}

\author{
Ana Carla Filgueira de Souza e Souza \\ https://orcid.org/0000-0002-9238-400X \\ Luciana Lyra Casais-e-Silva \\ https://orcid.org/0000-0003-3746-1348
}

Eduardo Pondé de Sena

https://orcid.org/0000-0002-6166-8093

Universidade Federal da Bahia- UFBa, Programa de Pós-graduação em Processos Interativos dos Órgãos e Sistemas, Salvador, Bahia, Brasil.

Conflict of interests: Nonexistent

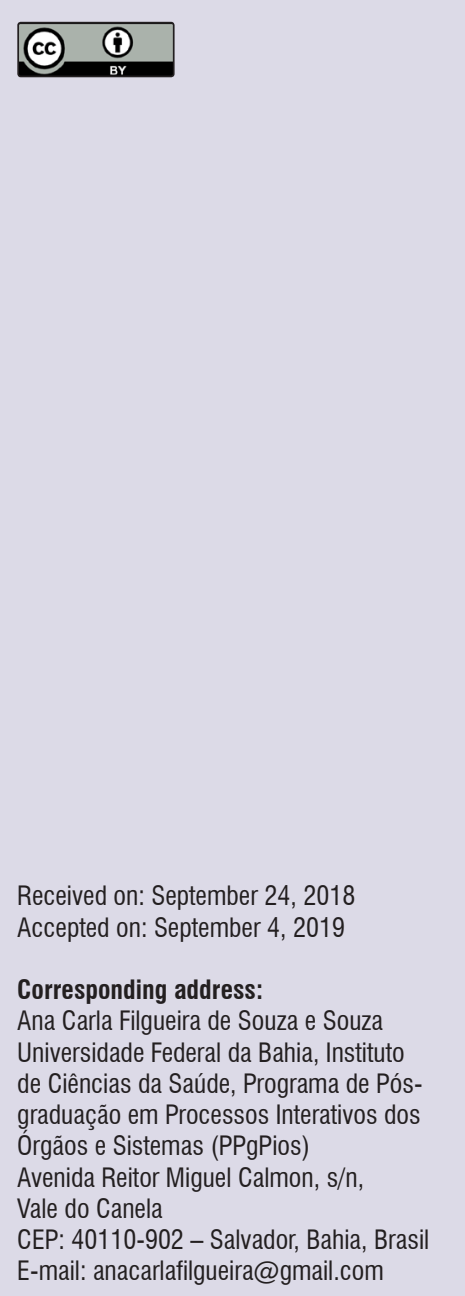

\section{ABSTRACT}

Purpose: to check the use of phonological processes in preterm infants.

Methods: phonological evaluation was performed through the ABFW Child Language Test in 40 children, aged two to four years, i.e., 20 preterm and 20 full-term children, matched according to age, gender and socioeconomic level. Preterm children were evaluated at the State Center for Prevention and Rehabilitation of People with Disabilities - CEPRED; full-term children were selected and evaluated in a municipal nursery in the city of Salvador, BA, Brazil. The pertinent statistical tests were applied adopting the level of significance lower than $0.05 \%$.

Results: in the phonology test, the number of productive phonological processes not expected for the chronological age was statistically significant in the preterm group, especially syllable reduction, consonantal harmony, velar backing and liquid reduction. The high prevalence of cluster reduction and final consonant deletion, though still compatible with chronological age, shows the need to follow up the language acquisition of these children, after the age of four.

Conclusion: the results evidenced the difficulty found by preterm infants in the development of phonological skills, emphasizing the importance of early diagnosis and speech-language monitoring in language acquisition.

Keywords: Newborn; Premature; Language Development; Language Development Disorders 


\section{INTRODUCTION}

In the past few years, studies have evidenced deviations in child development of preterm (PT) newborns. A research carried out by means of a population-based study review pointed to an increase in prematurity in Brazil, highlighting the importance of identifying the causes of such increase, and planning interventions to diminish the occurrence of premature births ${ }^{1}$. Preterm children have an increased risk of delays and deficits in many aspects of language ${ }^{2}$.

The World Health Organization defines as preterm (PT) every living neonate born before completing 37 weeks of pregnancy, counting from the first day of the last menstrual period; as full-term, those born between 37 and 41 weeks and six days; and post-term, when the pregnancy reaches a period beyond 42 weeks. Premature children may be classified as: extremely preterm, when birth takes place before 32 weeks of pregnancy; moderately preterm, when birth happens between 32 and 33 weeks; and late preterm, when birth occurs between 34 and 36 weeks of pregnancy ${ }^{3}$. It is known that the prevalence of prematurity in the world is around $7.2 \%$, whereas in Brazil it's 9.2\%, thus placed tenth among the countries with most premature births ${ }^{4}$.

As the survival rates for PT newborns increase, the conditions related to birth, such as prematurity and low birth weight (LBW), are risk factors that make the child more susceptible to alterations in development, among which, alterations in expressive language and in cognitive development, probably due to biological immaturity5,6.

A large portion of the studies that carried out a comparison between groups differentiated by gestational age verified that samples of children born PT presented worse performance in the language assessment tests, when compared to those born full-term, both in studies involving preschoolers and those with school age children ${ }^{7}$. PT born children, when in school age, have maintained the alterations, which suggests that the difficulty is continuous ${ }^{8,9}$.

Considering the higher nervous functions and not only the motor functions, the best indicator of child evolution may be considered to be the development of oral language, as it reflects not only a neurological maturation process, but also the manifestation of communicative, social, affective and intellectual skills significantly evolved and complex ${ }^{10}$. Hence, the development of language involves many processes, as its evolution depends on the interaction between biological, social, psychological and risk-related factors, such as prematurity and low weight, besides genetic aspects ${ }^{11}$.

Regarding the acquisition of the mother tongue, every particular grammatical aspect is considered. In general, studies show that, up to five years of age, the child has already acquired the grammar of their language. Therefore, identifying alterations, especially before school age, brings treatment forward and minimizes the damages, thus facilitating learning ${ }^{12}$. For people with typical language development, there's a sequence in the acquisition of phonological skills, beginning with the awareness of words, followed by rhymes, syllables and, lastly, phonemes ${ }^{13}$.

The phonological processes take place in the child's speech to make the production of phonemes easier, and result in adaptations in the speech patterns to the natural restrictions of human capability, which are observed in phoneme substitution. As the child develops and acquires their tongue, these processes must be overcome. The analysis of the processes allows phonology to be described, both in relation to development and deviations, enabling the establishment of priorities and strategies for the speechlanguage therapy ${ }^{14}$.

The greatest difficulty for children with phonological deviations is in understanding and/or using the phonological rules, and not necessarily in producing sounds. Thus, according to the evidences, it can be considered that the difficulty of these children lies in the linguisticcognitive organization of the phonological system of the language ${ }^{15}$. Studies have demonstrated that PT newborns may present fewer developed linguistic skills, such as phonology, leading to deviations ${ }^{16}$.

It is important to highlight that children in pre-school age diagnosed with phonological deviation may present difficulties in learning how to read and write. This issue emphasizes the need of having more and more evidence-based procedures allowing more efficiency in early diagnosis. The objective of this study was to verify the use of phonological processes in preterm children, assisted in a reference Specialized Rehabilitation Center in the state of Bahia, Brazil.

\section{METHODS}

This study was approved by the Research Ethics Committee of the Department of Health of the State of Bahia (SESAB), under the evaluation report 310,813/13. It met the guidelines for ethics with human beings, in accordance with Resolution 466/12 of the National Health Council - CNS. The Informed Consent Form was 
signed by the children's parents or those responsible for them, authorizing their participation in the research, after being fully instructed and accepting the participation in the study.

This is an observational, cross-sectional study. The sample was composed of 40 children, aged from two to four years, 28 females and 12 males; 20 were born preterm (preterm group - PTG), and 20 born full-term (control group - CG). The inclusion criteria for both groups were: presentation of the maternity discharge record, containing the gestational week, birth weight and any complications occurred at birth; absence of diagnosis of brain lesion, genetic syndrome and/or psychiatric alterations; absence of visual or auditory impairment, or any other condition making it impossible to carry out the activities proposed. The children who did not meet the established inclusion criteria, those who couldn't be reached through phone calls to schedule the assessment, and those who failed to attend the phonological assessment were excluded.

The CG was composed of children born full-term, with adequate birth weight, without alterations compromising language development, enrolled in a municipal nursery in the city of Salvador-BA, matched with the PTG in relation to gender, age and socioeconomic level. For the selection of the PTG, 200 medical records were analyzed at the State Center for Prevention and Rehabilitation of People with Disabilities (CEPRED) in Salvador, BA, Brazil, a unit belonging to the Public Health System (SUS, as abbreviated in Portuguese), authorized to function as a statewide reference Specialized Rehabilitation Center (CER) III, whose purpose is to develop actions towards secondary prevention, rehabilitation, and complete assistance to people with physical, auditory and intellectual disabilities and with ostomies, with a multiprofessional team, focusing on interdisciplinary work, by means of medium and high complexity actions. Following the analysis of the records, the children who met the selection criteria were summoned for phonological assessment at the CEPRED. All the children of the PTG had been accompanied by an interdisciplinary team up until their two years of age, and hadn't presented alterations in neuropsychomotor development, having thus been discharged before participating in this research.

The phonology assessment was performed using the naming and imitation tests of the ABFW - Child Language Test protocol ${ }^{17}$, validated in Brazil, indicated for children from two to twelve years old. In the imitation test, the child is asked to repeat each word given, until they reach 39 words. In the naming test, it's expected that the child, facing the stimulus represented by images or objects, say the expected word; this task consists of 34 images. The phonetic transcription of each word was written in both tests, and all the phonemes were analyzed, in agreement with the protocol.

The ABFW test ${ }^{17}$ classifies the productivity of the phonological processes, with the age established for the elimination of the productive use ranging from two and a half to seven years old, based on a research carried out with children without complaints of alterations in language, cognitive and motor development. A total of 14 phonological processes were analyzed, 10 of which were observed in the cases of phonological deviations: syllable reduction (bola - [bo]); consonantal harmony (macaco - [kakaku]); fricative stopping (sopa - [topa] / varal - [baraw]); velar backing (todo - [kogu]); palatal backing (sino - [inu] / zero - [3Ero]); velar fronting (cara - [tara]); palatal fronting (chalé - [sale] / gelado - [zeladu]); liquid reduction (bala - [baya] / alho - [ayu] or [alu] / barata - [balata] or [bayata]); cluster reduction (braço - [basu] or [blasu] / planta [pãta]); and, final consonant deletion (amor - [amo] / susto - [sutu]).

The phonological processes were analyzed according to their occurrence. Hence, those with more than $25 \%$ of occurrence in each test are called productive (PPP), whereas those with less than $25 \%$ of occurrence are called non-productive (NPPP) ${ }^{17}$. All the tests were individually recorded and applied, in adequate well-lit environment, without any competing visual and/or auditory stimuli, or any other distracting factors that might interfere with the assessment. The manner of assessement was rigorously maintained, as specified for each area assessed. During test application, the evaluator sat in front of the subject, while the application material and the record sheets remained on the table.

For the association analysis, the McNemar test and the Wilcoxon test were used. In order to identify whether there had been statistical difference in the production averages in the phonological processes, the Mann-Whitney test was used. The chi-squared test was used to test the association between the prematurity and phonological deviation variables. As statistical significance level, $p<0.05$ was considered. The data were charted and processed in electronic spreadsheets in the SPSS software, version 20.0. 


\section{RESULTS}

The PTG was composed of 20 children, 14 females and 6 males, aged from two to four years. The gestational age ranged from 26 to 36 weeks, with median of 32 weeks; birth weight ranged from 530 to $2,310 \mathrm{~g}$, with median of $1,647.5 \mathrm{~g}$. The CG was composed of 20 children born full-term, matched to the PTG children in age and gender. The data referring to the phonological processes may be observed in Tables 1 and 2 .

The McNemar test was used to verify the association between both groups in the imitation and naming tests, indicating when the collected data match; for each case (PTG) there was only on control (CG). It was noted that $X^{2}{ }_{M C N}=5.79(p=0.0162)$, so there was a difference between the proportions of children with phonological deviation in both groups analyzed. Therefore, association was noticed between prematurity and the presence of phonological deviation in the sample of this study. The odds ratio calculated in the McNemar test is given at $12 / 2=6$. Thus, a child in the PTG was six times more likely to develop a phonological deviation, when compared to a child in the CG. Considering the confidence level at $95 \%$, a confidence interval of 1.34 ; 26.81 was found.

By means of the Wilcoxon test, it was observed that, in the naming and imitation tasks, there was a significant difference $(p<0.05)$ between the productivity averages in both groups analyzed, in the phonological processes of syllable reduction and consonantal harmony (elimination expected by 2.6 years old); velar backing $(p=0.03)$ and liquid reduction (elimination expected by 3.6 years old); cluster reduction and final consonant deletion (elimination expected around 5 years old), as it can be observed in Tables 1 and 2. In spite of cluster reduction and final consonant deletion being still compatible with the age group investigated in this study, greater prevalence of these processes was noticed in PTG.

Table 1. Average productivity of the phonological processes in the naming test

\begin{tabular}{lccc}
\hline \multirow{2}{*}{ Phonological Process } & \multicolumn{3}{c}{ Groups } \\
\cline { 2 - 4 } & PTG (average \%) & CG (average \%) & p value \\
\hline Syllable reduction & 7.4 & 0.0 & 0.04 \\
Consonantal harmony & 5.2 & 0.0 & 0.03 \\
Fricative stopping & 14.5 & 5.3 & 0.21 \\
Velar backing & 8.0 & 0.0 & 0.07 \\
Palatal backing & 5.1 & 0.5 & 0.20 \\
Velar fronting & 12.3 & 5.0 & 0.50 \\
Palatal fronting & 12.2 & 5.0 & 0.28 \\
Liquid reduction & 63.6 & 27.7 & 0.01 \\
Cluster reduction & 97.8 & 46.2 & 0.01 \\
Final consonant deletion & 47.8 & 22.0 & 0.00 \\
\hline
\end{tabular}

Legend: PTG - Preterm group; CG - Control group.

The Wilcoxon test was used, at the significance level of $0.05(5 \%)$, with differences being significant only if $p<0.05$. 
Table 2. Average productivity of the phonological processes in the imitation test

\begin{tabular}{lccc}
\hline \multirow{2}{*}{ Phonological Process } & \multicolumn{3}{c}{ Groups } \\
\cline { 2 - 4 } & PTG (average \%) & CG (average \%) & p value \\
\hline Syllable reduction & 5.8 & 0.0 & 0.02 \\
Consonantal harmony & 4.8 & 0.0 & 0.02 \\
Fricative stopping & 11.1 & 4.5 & 0.34 \\
Velar backing & 9.0 & 0.0 & 0.03 \\
Palatal backing & 7.1 & 1.4 & 0.27 \\
Velar fronting & 11.3 & 5.0 & 0.24 \\
Palatal fronting & 11.5 & 3.3 & 0.24 \\
Liquid reduction & 62.7 & 26.4 & 0.01 \\
Cluster reduction & 96.3 & 41.6 & 0.00 \\
Final consonant deletion & 42.7 & 15.7 & 0.00 \\
\hline
\end{tabular}

Legend: PTG - Preterm group; CG - Control group.

The Wilcoxon test was used, at the significance level of $0.05(5 \%)$, with differences being significant only if $p<0.05$.

The Mann-Whitney test was used to identify whether there was statistical difference in the production averages in the phonological processes compatible and incompatible with the chronological age group of the PTG. In Table 3, it can be observed that there was a significant difference in the processes of velar backing $(p=0.01)$ and liquid reduction $(p=0.01)$, both expected to be absent by 3.6 years old.

Table 3. Average productivity of the phonological processes compatible and incompatible with the chronological age in the preterm group

\begin{tabular}{lccc}
\hline \multirow{2}{*}{ Phonological Process } & \multicolumn{3}{c}{ Use of phonological process } \\
\cline { 2 - 4 } & Incompatible & Compatible & p value \\
\hline Syllable reduction & 2.75 & 2.8 & 0.77 \\
Consonantal harmony & 2.6 & 2.1 & 0.70 \\
Fricative stopping & 11.4 & 5.5 & 0.46 \\
Velar backing & 8.2 & 1.9 & 0.01 \\
Palatal backing & 9.2 & 1.2 & 0.09 \\
Velar fronting & 7.4 & 8.3 & 0.33 \\
Palatal fronting & 11.2 & 4.9 & 0.22 \\
Liquid reduction & 62.2 & 32.7 & 0.02 \\
Cluster reduction & 0 & 100 & 0.83 \\
Final consonant deletion & 0 & 100 & 0.83 \\
\hline
\end{tabular}

The Mann-Whitney test was used, at the significance level of $0.05(5 \%)$, with differences being significant only if $p<0.05$.

Figure 1 shows the use of phonological processes by age in the PTG, and it is observed that at two years old, there was an absence of incompatible phonological processes; at three years old, $50 \%$ present incompatible phonological processes, such as syllable reduction and consonantal harmony; and, at four years old, $70 \%$ of the children presented processes incompatible with what is expected, as velar backing and liquid reduction.

By applying the chi-squared test to verify the association between the prematurity and phonological deviation variables in the sample, an association between the two variables studied $\left(\mathrm{X}^{2}=6.23\right.$ with $2 \mathrm{DF}$ and $p=0.044$ ), was observed. 


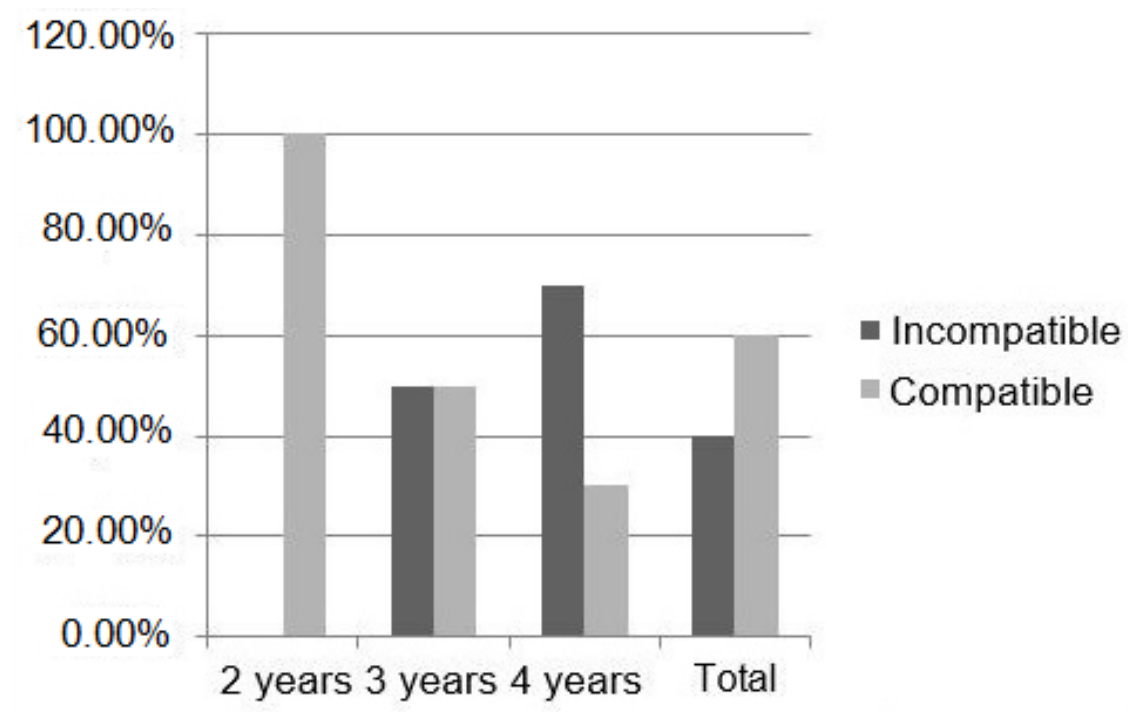

Source: research data.

Figure 1. Classification of the use of phonological processes, according to the age range in the preterm group

\section{DISCUSSION}

In this study, better performance of the CG has been noted in relation to the use of phonological processes. The significant number of phonological processes persisting in the PTG may be related to prematurity, agreeing with the findings of other authors ${ }^{18}$. Attention is called to the fact that both groups presented similar exposure concerning non-linguistic risk factors, such as socioeconomic and cultural aspects. The age group investigated in this study represents the time when the greatest change in the phonological system of the child takes place; thus, the importance of verifying and comparing the phonological acquisition of PT and full-term children.

The forming of phonological representations is strongly conditioned by the brain maturation factors. One of the important aspects to be questioned is the amount of exposure the children have to the language during social interaction, and what resources are used for interacting with the physical environment and with people ${ }^{19}$. Even though there are in both national and international literature many studies on the language development of PT children, there is a shortage of researches on the acquisition of phonological skills in this population, especially in relation to the use of the phonological processes. There are reports of alterations in speech and/or language being common in children born PT, including deviations in phonological acquisition. Even in the absence of brain lesion, brain maturation and vulnerability imposed by early entrance into the extrauterine environment are associated with structural and microstructural changes on the brain. The possible complications are associated with alterations in language, with effects on childhood and adolescence, there being a need of phonological follow-up in these cases $^{20}$.

In the PTG, it has been consistently observed the occurrence of the phonological processes of velar backing, liquid reduction, cluster reduction and final consonant deletion, regardless of the degree of prematurity presented by the children. The two-yearold children's not presenting phonological processes incompatible with the chronological age (which does not happen with three- and four-year-old children) warns of the need of systematic follow-up of PT born children, in order to monitor this skill in its acquisition stage, preventing future alterations and avoiding late diagnosis. A study carried out with 134 children between the ages of one and five years with adequate phonological development observed that, in general, the phonological processes were used differently by the younger children in relation to the older ones. It was evidenced that the variety and the amount of strategies used are usually greater among children aged between one and three years, becoming more restricted and less used in those aged from three to five years ${ }^{21}$. The same has been observed in the CG of this study, since the amount of phonological processes decreased as the age increased, which did not occur with the PTG. 
It is known that until two years of age, oral expression is the most affected component, and that, from three to twelve years of age, delays in other skills may take place, regardless of the degree of prematurity ${ }^{22,23}$. At 20 months of age, PT children, who have linguistic development inferior to that of full-term children, will probably maintain such performance in future years. This suggests that language assessment in the first years of life is highly predictive of future skills and may indicate the need of intervention ${ }^{24}$.

Other phonological processes were also considered productive in the PTG, according to the parameters proposed by the ABFW test ${ }^{17}$, in all age groups, though compatible with the expected for the respective chronological age. The high number of occurrences warns of the great difficulty found by the PT children in producing syllabic structures in early childhood. A study carried out with children with typical phonological development found that, at the age of three, cluster reduction and final consonant deletion were also observed to be very frequent. It is expected that in children with typical development these processes decrease as the age increases ${ }^{25}$. However, it has been verified in this study that the children in the PTG maintained the use of phonological processes incompatible with their age, attention being called especially to the age of four. An investigation into the age group posterior to this one is made necessary to verify whether the processes persist.

Regarding liquid reduction, the substitution and omission of trills have been observed, whereas the semivocalization did not occur, thus, highlighting the regional characteristics and the varying phonological acquisition due to sociolinguistic context of the child. Although there is a certain sequence and pace in phonological development, it is believed that each person develops language in a particular way; therefore, individual variations should be considered ${ }^{26}$. No reports on the persistency of the process of velar backing in PT children were found in literature, or on other risk factors for phonological acquisition.

When investigating children between four and twelve years old diagnosed with phonological deviations, it was demonstrated that, in the analysis of the phonological processes, the non-productive processes were registered in greater number than the productive processes, both in the naming and in the imitation test, using the ABFW test ${ }^{17}$ as instrument. It was observed that in both tests more people presented the processes of liquid reduction, cluster reduction and final consonant deletion, regardless of productivity ${ }^{15}$. This study allowed it to be verified that there has been agreement between the imitation and the naming tests, and that the findings in the PTG are compatible with other studies which investigated children with phonological deviations, since the process of liquid reduction was also observed in the age group of four years.

The acquisition and integration of cognitive and linguistic skills depend on individual factors, but they also depend on environmental and social interactions, especially during the first years of life, highlighting the crucial role of early childhood ${ }^{27}$. Gestational age was not associated with alterations in language development in children born PT evaluated in the age group between 10 and 30 months. Nevertheless, the authors of the study emphasize that such finding may be related to the low-risk characteristics of the sample, without serious medical complications ${ }^{28}$. A cohort study evidenced high incidence of specific linguistic alterations in the premature children at the age of five, though without precision to define future impairment, emphasizing the need of continuous evaluation in order to investigate risks of psychosocial and academic problems ${ }^{29}$. It is known that there is a long-term significant impact and it may affect the child's social relations, literacy and educational stages. Literature associates alterations in linguistic skills to the risk of failure in school, as well as psychosocial and emotional alterations. Hence, there's a need of effective follow-up strategies, such as scanning, evaluation and monitoring of the child's development ${ }^{30,31}$.

Generally, literature points to the effects of prematurity in relation to language acquisition, either being comorbidities of other clinical conditions associated to prematurity or related to prematurity itself, as a biological risk factor ${ }^{32}$. Alterations in language are frequently found in this population. More specifically, PT children present difficulty in all linguistic subdomains, including phonology, semantics, grammar, discourse and pragmatics ${ }^{33}$. Even mild delays in development resulting from prematurity may cause negative consequences, from difficulties in school to the inability to live fully independently ${ }^{34}$. Thus, these children may not recover the delay in development, causing consequences that would affect their academic performance as well. The midterm and long-term follow-up, before the child enters schools, is a means of identifying possible deviations and prevent repercussions in school learning ${ }^{35}$. Therefore, the early recognition of alterations in language acquisition allows the child to 
be benefitted from the speech-language intervention, improving their linguistic skills and reducing the risk of persisting alterations ${ }^{36}$.

The findings of this study warns of the need of careful and standardized evaluations, emphasizing the importance of including speech-language assessment in the clinical evaluation procedures for children with history of prematurity, since the assessment of language represents a critical component for clinical diagnosis. In addition, it aids in therapy, as it makes it possible to identify which phonological process must be begun with, in order to obtain a faster and more efficient treatment. The early identification of deviations is essential for improving the children's functional result.

\section{CONCLUSION}

In this study, it was evidenced that PT children present phonological processes incompatible with chronological age, whereas the same did not occur with the full-term children, in the CG. The most prevalent phonological processes incompatible with the age group of the PTG were: syllable reduction, consonantal harmony, velar backing, and liquid reduction, especially at the age of four.

It is possibility that the findings relate to neurologic immaturity caused by prematurity. Thus, this study shows the need of speech-language follow-up of children presenting risk factors for language development deviations, such as prematurity. Longitudinal studies that follow up the development of phonological skills of children born preterm are necessary, since such monitoring would favor the understanding of the process of their development, benefitting the prevention of deleterious effects in their language acquisition.

\section{REFERENCES}

1. Silveira MF, Santos IS, Matijasevich A, Malta DC, Duarte EC. Nascimentos pré-termo no Brasil entre 1994 e 2005 conforme o Sistema de Informações sobre Nascidos Vivos (SINASC). Cad. Saúde Pública. 2009;25(6):1267-75.

2. Wolke D, Strauss VY-C, Johnson S, Gilmore C, Marlow N, Jaekel J. Universal gestational age effects on cognitive and basic mathematic processing: 2 Cohorts in 2 countries. J Pediatr. 2015;166(6):1410-6.

3. Blencowe H, Cousens S, Oestergaard MZ, Chou D, Moller $A B$, Narwal $R$ et al. National, regional, and worldwide estimates of preterm birth rates in the year 2010 with time trends since 1990 for selected countries: a systematic analysis and implications. Lancet. 2012;379(9832):2162-72.

4. de Almeida A, de Jesus A, Lima P, de Araujo $M$, de Araulo $T$. Fatores de risco maternos para prematuridade em uma maternidade pública de Imperatriz-MA. Rev Gaucha Enferm. 2012;33(2):86-94.

5. Lamônica DAC, Carlino F, Alvarenga K. Avaliação da função auditiva receptiva, expressiva e visual em crianças prematuras. Pro Fono R Atual Cient. 2010;22(1):19-24.

6. Silva GMD, Couto MIV, Molini-Avejonas DR. Risk factors identification in children with speech disorders: pilot study. CoDAS. 2013;25(5):456-62.

7. Woodward LJ, Moor S, Hood KM, Champion PR, Foster-Cohen S, Inder TE et al. Very preterm children show impairments across multiple neurodevelopmental domains by age 4 years. Arch Dis Child Fetal Neonatal. 2009;94(5):339-44.

8. Barre N, Morgan A, Doyle LW, Anderson PJ. Language abilities in children who were very preterm and/or very low birth weight: a meta-analysis. J Pediatr. 2011;158(5):766-74.

9. Lee ES, Yeatman JD, Luna B, Feldman HM. Specific language and reading skills in school-aged children and adolescents are associated with prematurity after controlling for IQ. Neuropsychologia. 2011;49(5):906-13.

10. Zorzi JL. Aspectos básicos para compreensão, diagnóstico e prevenção dos distúrbios de linguagem na infância. Rev. CEFAC. 2000;2(1):11-5.

11. Hay DA, Preedy P. Meeting the educational needs of multiple birth children. Early Hum Dev. 2006;82(6):397-403.

12. Lorandi A, Cruz CR, Scherer APR. Aquisição da linguagem. Verba Volant. 2011;2(1):144-66.

13. Wertzner HF, Pagan LO, Galea DES, Papp ACCS. Características fonológicas de crianças com transtorno fonológico com e sem histórico de otite média. Rev Soc Bras Fonoaudiol. 2007;12(1):41-7.

14. Yavas M, Hernandorena CLM, Lamprecht RR. Avaliação fonológica da criança: reeducação e terapia. Porto Alegre: Artes Médicas; 1992.

15. Wertzner HF, Papp ACCS, Galea DES. Provas de nomeação e imitação como instrumentos de diagnóstico do transtorno fonológico. Pro Fono $\mathrm{R}$ Atual. Cient. 2006;18(3):303-12. 
16. Guarini A, Sansavini A, Fabbri C, Alessandroni R, Faldella G, Karmiloff-Smith A. Reconsidering the impact of preterm birth on language outcome. Early Hum Dev. 2009;85(10):639-45.

17. Andrade CRF, Befi-Lopes DM, Fernandes FDM, Wertzner WH. ABFW - Teste de Linguagem infantil nas áreas de Fonologia, Vocabulário, Fluência e Pragmática. 2a ed. Barueri: Pró-Fono; 2011.

18. Lamônica DAC, Picolini MM. Habilidades do desenvolvimento de prematuros. Rev. CEFAC. 2009;11(2):145-53.

19. Peña M, Werker JF, Dehaene-LambertzG. Earlier speech exposure does not accelerate speech acquisition. J Neuroscience. 2012;32(33):11159-63.

20. Vohr B. Speech and language outcomes of very preterm infants. Sem Fetal Neonatal Med. 2014;19(2):78-83.

21. Ribas LP. Onset complexo: características da aquisição. Letras Hoje. 2003;38(2):23-31.

22. Ribeiro CD, Pachelli MR, Amaral NC, Lamônica DA. Development skills of children born premature with low and very low birth weight. CoDAS. 2017;29(1):e20160058.

23. Zerbeto AB, Cortelo FM, Carvalho Filho EB. Association between gestational age and birth weight on the language development of brazilian children: a systematic review. J Pediatr. 2015;91(4):326-32.

24. Putnick DL, Bornstein MH, Eryigit-Madzwamuse S, Wolke D. Long-term stability of language performance in very preterm, moderate-late preterm, and term children. J Pediatr. 2017;181:74-9.

25. Ferrante C, Borsel JV, Pereira MMB. Análise dos processos fonológicos em crianças com desenvolvimento fonológico normal. Rev Soc Bras Fonoaudiol. 2009;14(1):36-40.

26. Queiroga BAM, Alves JM, Cordeiro AAA, Montenegro ACA, Asfora R. Aquisição dos encontros consonantais por crianças falantes do português não padrão da região metropolitana do Recife. Rev. CEFAC. 2011;13(2):214-26.

27. Castelli RD, Quevedo LA, Coelho FMC, Lopez MA, Silva RA, Böhm DM et al. Cognitive and language performance in children is associated with maternal social anxiety disorder: a study of young mothers in southern Brazil. Early Hum Dev. 2015;91(12):707-11.

28. Pérez-Pereira $M$, Fernández $P$, Gómez-Taibo $M L$, Resches M. Language development of low risk preterm infants up to the age of 30 months. Early Hum Dev. 2014;90(10):649-56.
29. Woods PL, Rieger I, Wocadlo C, Gordon A. Predicting the outcome of specific language impairment at five years of age through early developmental assessment in preterm infants. Early Hum Dev. 2014;90(10):613-9.

30. Lee ES, Yeatman JD, Luna B, Feldman HM. Specific language and reading skills in school-aged children and adolescents are associated with prematurity after controlling for IQ. Neuropsychologia. 2011;49(5):906-13.

31. Lamego D, Bastos O, Moreira M. Diretrizes para a saúde da criança: o desenvolvimento da linguagem em foco. Cien Saude Colet. [periódico na internet] 2016; [citado em 07/03/2018] 23(9):3095-3106. Disponível em: http://www.cienciaesaudecoletiva. com.br/artigos/diretrizes-para-a-saude-da-criancao-desenvolvimento-da-linguagem-em-foco/15932

32. Rechia IC, Oliveira LD, Crestani AH, Biaggio EPV, Souza APR. Effects of prematurity on language acquisition and auditory maturation: a systematic review. CoDAS. 2016;28(6):843-54.

33. Reidy N, Morgan A, Thompson DK, Inder TE, Doyle LW, Anderson PJ. Impaired language abilities and white matter abnormalities in children born very preterm and/or very low birth weight. J Pediatr. 2013;162(4):719-24.

34. Maxwell JR, Yellowhair TR, Oppong AY, Camacho JE, Lowe JR, Jantzie LL et al. Cognitive development in preterm infants: multifaceted deficits reflect vulnerability of rigorous neurodevelopmental pathways. Minerva Pediatr. 2017;69(4):298-313.

35. Félix J, Santos ME, Benítez-Burraco A. Spontaneous language of preterm children aged 4 and 5 years. Rev. CEFAC. 2017;19(6):742-8.

36. Wallace IF, Berkman ND, Watson LR, CoyneBeasley T, Wood CT, Cullen K. Screening for speech and language delay in children 5 years old and younger: a systematic review. Pediatrics. 2015;136(2):e448-e62. 